\title{
Obstructive Sleep Apnea Syndrome, Periodic Limb Movements and Related Factors
}

\author{
Obstrüktif Uyku Apne Sendromu, Periyodik Bacak Hareketleri ve İlişkili Faktörler
}

\author{
Osman Özgür Yalın¹, İbrahim Arda Yılmaz², Mehmet Ali Sungur ${ }^{3}$, Okan Doğu² \\ 1 İstanbul Education and Research Hospital, Clinic of Neurology, İstanbul, Turkey \\ 2Mersin University School of Medicine, Department of Neurology, Mersin, Turkey \\ 3Düzce University School of Medicine, Department of Biostathistics, Düzce, Turkey
}

\section{Summary}

Objective: Obstructive sleep apnea syndrome (OSAS) is characterized by repetitive nocturnal apnea episodes. Periodic limb movements (PLMs) is known as the nocturnal, stereotypic, repetitive movements of the lower extremities. The aim of this study was to investigate the presence of PLMs in patients with OSAS, and the relationship between PLM and OSAS severity.

Materials and Methods: One hundred forty-one patients who had a pre-diagnosis of OSAS were enrolled into the study. All subjects' blood pressure, heart rate measurements, and neurologic examinations were performed by the same neurologist. Sociodemographic characteristics were recorded. Overnight polysomnography (PSG) was performed in all patients and results were analyzed. Patients with an apnea-hypopnea index (AHI) of $\geq 5$ were accepted as having OSAS, and a PLM index (PLMI) of $\geq 5$ were accepted as having PLM.

Results: One hundred two patients were diagnosed as having OSAS. The control group consisted of 39 patients who had normal polysomnographic findings. The patients with OSAS were older and their body mass indexes (BMI) were higher compared with the control group. Systolic blood pressure was higher in the OSAS group. Alcohol use was found to be a risk factor for OSAS. PLM was more common in the OSAS group than in the control group (30.3-10.2\%). PLM frequency was associated with the severity of OSAS.

Conclusion: The presence of PLM was associated with OSAS severity, higher systolic and diastolic blood pressure, and REM sleep depletion in OSAS. PLM seen in patients with OSAS may be regarded as an indicator of disease severity, and should alert the physician to increased complications.

Keywords: Obstructive sleep apnea syndrome, periodic limb movements, polysomnography

\section{$\ddot{O} \mathbf{z}$}

Amaç: Obstrüktif uyku apne sendromu (OUAS) uykuda sık tekrarlayan apneler ile karakterize bir bozukluktur. Periyodik bacak hareketleri (PBH) alt ekstremitelerde uyku sırasında ortaya çıkan, tekrarlayıcı ve stereotipik özelliği olan hareketlerdir. Bu çalışmada OUAS'da PHB varlığı ve PBH'nin OUAS şiddeti ile ilişkisi araştırıldı.

Gereç ve Yöntem: OUAS ön tanılı 141 birey çalışmaya dahil edildi. Katılımcıların kan basıncı, nabız ölçümleri, nörolojik muayeneleri yapıldı. Hastaların tümüne 1 gece süreyle polisomnografi incelemesi yapıldı ve sonuçlar analiz edildi. Polisomnografi incelemesinde apne hipopne indeksi (AHI) $\geq 5$ olması OUAS, periyodik bacak hareket indeksi (PBHI) $\geq 5$ olması PBH olarak kabul edildi.

Bulgular: Yüz iki hasta OUAS tanısı aldı. Polisomnografi incelemesi normal saptanan 39 birey kontrol grubunu oluşturdu. OUAS hastaları daha yaşlı ve vücut kitle indeksi (VKİ) daha yüksek bulundu. Sistolik kan basıncı OUAS grubunda daha yüksekti. Alkol kullanımı OUAS için risk faktörü olarak saptandı. PBH'nin OUAS hastalarında kontrol grubuna göre daha sık olduğu gözlendi (\%30,3-10,2). PBH sıklı̆̆ı OUAS şiddetine paralel olarak artmaktaydı. 


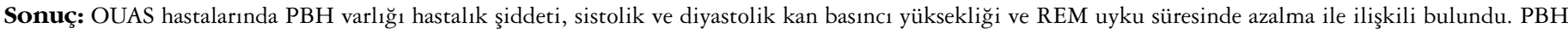
varlığı OUAS hastalarında hastalık şiddetinin bir göstergesi olarak kabul edilebilir ve klinisyeni artmış komplikasyon riskleri açısından uyarabilir.

Anahtar kelimeler: Obstruktif uyku apne sendromu, periyodik bacak hareketleri, polisomnografi

\section{Introduction}

Obstructive Sleep Apnea Syndrome (OSAS) is characterized by repetitive pharyngeal collapse and transient apnea episodes due to loss of dilatatory pharyngeal muscle tonus (1). OSAS is seen in $4-20 \%$ of adults in the population. Fifty percent of obese males are known to have the disorder and the prevalence increases with body mass index (BMI) (2). OSAS has been associated with daytime sleepiness, fatigue, and negative effects on social life as well as cardiovascular diseases and elevated risk of sudden death $(3,4)$. OSAS poses a significant public health problem that requires early diagnosis and treatment because it is a common disorder and has a modifiable risk factor (4).

Periodic leg movements (PLM) is a clinical picture comprising of involuntary, repetitive, stereotypical, brief, and segmental movements, often of the lower extremities during sleep. PLM affects slightly more than $6 \%$ of the population (5) and $65 \%$ of the elderly population aged over 65 years (6). PLM have been associated with restless leg syndrome (RLS), which is reported in more than $80 \%$ of patients with RLS (7). PLM are also common in several sleep disorders including OSAS, narcolepsy, and rapid eye movement (REM) sleep behavior disorder (8). In their retrospective study that examined 798 subjects, Al-alawi et al. (6) reported PLM in half of all patients with OSAS, and associated the presence of PLM with advanced age and increased weight. Authors have also reported that PLM in association with OSAS does not influence daytime sleepiness or blood pressure (6). However, other studies have reported that PLM in patients with OSAS is associated with increased daytime symptoms (9). There are growing numbers of reports that suggest PLM as a novel risk factor in hypertension, cardiovascular, and cerebrovascular disorders $(10,11)$. A recent study found a relationship between PLM and elevated diastolic blood pressure, irrespective of the apnea-hypopnea index (AHI) (12). PLM has also been reported to be a component of chronic diseases including congestive heart failure, chronic renal failure, Parkinson's disease, and sleep apnea (11).

The objective of this study was to determine the prevalence of PLM in patients with sleep apnea, and investigate the relationship between PLM and OSAS severity. Additionally, we aimed to study the relationship of the presence of PLM in patients with OSAS and blood pressure, sleep efficacy and duration, and REM sleep.

\section{Materials And Methods}

\section{Patients}

Subjects who were pre-diagnosed as having OSAS at the Neurology Outpatients' clinic upon presentation with symptoms of snoring, apnea, daytime sleepiness, and fatigue during the 6-month period of study recruitment were included in this study. The study protocol was approved by the Ethics Committee of Mersin University Medical Faculty (Decree number 2008/126) prior to the performance of any study procedures. All patients provided written informed consent after being informed of the study procedures. A total of 141 patients were interviewed. The patients were assessed using a structured interview scale. Demographic features including age, sex, height, weight, and education level were recorded. Status of smoking and alcohol consumption as well as mean amounts and duration, concomitant diseases, and medication history were questioned. Following the completion of the interview scale, the study physician performed a neurologic examination, blood pressure, and pulse measurements of all patients at the outpatients' clinic.

Patients with restless leg syndrome, history of cerebrovascular disease, restricted cooperation due to other diseases, or those using medications that could potentially affect the polysomnography examination were excluded from the study.

\section{Polysomnography}

All patients underwent overnight polysomnography. Surface electrodes were used for electroencephalog raphic recordings (C3-A2 and $\mathrm{C} 4-\mathrm{A} 1, \mathrm{O} 1-\mathrm{A} 2$ and $\mathrm{O} 2-\mathrm{A} 1)$. Electrodes were placed to obtain bitemporal electrooculographic, submental, electromyographic (bilateral tibialis anterior) and electrocardiographic recordings. Thoracic and abdominal pneumobands were placed in a pressure transducer to record changes in thorax and abdomen movements. A pulse oximeter was placed on the patients' fingertips and the findings were recorded using an EMLA S7000 device (Flaga hf. Medical Devices, Iceland) by a certified technician for at least six hours during the polysomnography.

Polysomnography recordings were scored using 30-second long epochs using the Somnologica 3.3.2 (Flaga Inc) software. Sleep recordings were assessed using 30-second epochs and staged in accordance with the guideline criteria released by the American Academy of Sleep Medicine (AASM) (13). Automatic analyses of apnea and hypopnea were double-checked by the study physician. The AHI was obtained by dividing the total sum of apnea and hypopnea count with the duration of sleep in hours. Patients with an AHI $\geq 5$ were defined as patients with OSAS; those with an AHI 5-15 were classified as mild, 16-30 as moderate, and >30 were classified as having severe OSAS. Stages of sleep were scored as N1, N2, N3, and REM sleep. Leg movements were also scored in accordance with the AASM guidelines; i.e. leg movements lasting $0.5-10$ seconds and causing a minimum of $8 \mu \mathrm{V}$ increase in resting EMG activity were scored. PLM was described as $\geq 4$ consecutive movements lasting 5-90 seconds (14). The PLM index (PLMI) was calculated by dividing the total count of periodic leg movements with the duration of sleep in hours. Leg movements associated with respiration were excluded from analysis; hence the conventional definition of PLMI $\geq 5$ was considered positive for PLM (13).

\section{Statistical Analysis}

The relationship between categorical data was tested using Chi-square or Fisher's exact Chi-square test, continuous data were compared with the independent samples t-test in parameters with uniform distribution, and the Mann-Whitney $U$ test for 
parameters with non-uniform distribution. One-way ANOVA was used to compare more than two groups. Risk factors of diseases were determined with logistic regression analysis. Descriptive statistics were presented as mean \pm standard deviation, median, and interquartile intervals, and categorical data were presented as frequency and percentages. All analyses were performed with the Predictive Analytics Software (PASW; a registered trademark of SPSS Inc.) version-18 package. A p value $<0.05$ was considered statistically significant.

\section{Results}

The total of 141 study patients comprised 104 men $(73.8 \%)$ and 37 women $(26.2 \%)$. The age range of the study group was between $18-79$ years and mean age was $47.3 \pm 11.3$ years. One hundred two patients $(72.3 \%)$ were diagnosed as having OSAS due to AHI $\geq 5$. The control group consisted of 39 patients $(27.7 \%)$, who had normal polysomnography. The mean age in the OSAS group was $49.3 \pm 11.3$ years, and $41.9 \pm 9.2$ years in the control group. The patient group was statistically significantly older $(\mathrm{p}<0.001$; Table 1$)$. The OSAS group consisted of 80 men (78.4\%) and 22 women (21.6\%); the control group comprised 24 men $(61.5 \%)$ and 15 women $(38.5 \%)$. Men were predominant in both groups. There were statistically significantly more men in the OSAS group compared with the control group (78.4\% vs. $61.5 \%$; $\mathrm{p}=0.041$ ). The mean BMI was $31.6 \pm 5.8 \mathrm{~kg} / \mathrm{m}^{2}$ in the OSAS group, and $27.3 \pm 4.6 \mathrm{~kg} / \mathrm{m}^{2}$ in the control group. BMI was statistically significantly higher in the OSAS group $(\mathrm{p}<0.001)$. Additionally, all patients with BMI>36 had severe OSAS. Alcohol consumption and systolic blood pressure values were statistically significantly greater in the OSAS group $(\mathrm{p}=0.006$ and $\mathrm{p}=0.049$, respectively). Smoking rates were comparable in both groups $(\mathrm{p}=0.987)$.

Patients with PLM had significantly higher AHI $(\mathrm{p}<0.001)$ and shorter REM durations $(\mathrm{p}=0.003)$, were significantly older $(\mathrm{p}=0.020)$ and more overweight $(\mathrm{p}=0.002)$. Systolic and diastolic blood pressure was higher in patients with PLM ( $\mathrm{p}=0.004$ and $\mathrm{p}=0.010$, respectively; Table 2 ).
PLM was identified in $19.4 \%$ of patients with mild OSAS, $29.2 \%$ of patients with moderate OSAS, and $57.4 \%$ of those with severe OSAS (Table 3). A statistically significant relationship was determined between the severity of OSAS and the presence of PLM ( $p=0.002)$. A comparison of patients with OSAS with regard to age revealed that patients with mild OSAS were statistically significantly younger than patients with moderate and severe OSAS ( $\mathrm{p}=0.009)$. A comparison with regard to BMI revealed that patients with severe OSAS weighed significantly more compared with patients with mild and moderate OSAS $(\mathrm{p}<0.001)$. Systolic blood pressure was greater in patients with severe OSAS ( $\mathrm{p}=0.035)$, but diastolic blood pressure was comparable between the groups $(\mathrm{p}=0.228$; Table 3).

\section{Discussion}

In our study, PLM was determined in $30.3 \%$ of patients with OSAS and $10.2 \%$ of the control group. PLM was particularly predominant in patients with severe OSAS (17\% with mild OSAS, $23 \%$ with moderate OSAS, and $43 \%$ with severe OSAS). In the study of Haba-Rubio et al. (15), PLM was reported in $38.5 \%$ of patients with OSAS. Our results are in line with those reported in the literature. The study of Baran et al performed in 2003 on patients with OSAS and PLM demonstrated that CPAP therapy provided a reduction in the PLM index in patients with mild OSAS, whereas no improvement was seen in PLM in patients with moderate or severe OSAS (16). In their study, Carelli et al. (17) demonstrated that apnea and hypopneas improved but PLM remained unchanged with CPAP therapy, and that OSAS and PLM did not originate from identical generators.

The frequency of PLM is known to increase with age, and our results demonstrated that the PLM group was older and incidence increased with OSAS severity. Manconi et al. (18) associated leg movements during sleep with increased AHI. PLM was described in $59.5 \%$ of patients with OSAS when PLMI was accepted as $\geq 5$, and authors have suggested that the presence of PLM might indicate a different patient group. Our results were in line with the latter

Table 1. Clinical and polysomnography findings of obstructive sleep apnea syndrome and control groups

\begin{tabular}{|l|l|l|l|}
\hline & OUAS $(\mathbf{n}=102)$ & Control $(\mathbf{n}=39)$ & $\mathrm{p}$ \\
\hline Age & $49.3 \pm 11.3$ & $41.9 \pm 9.2$ & $<0.001$ \\
\hline BMI & $31.6 \pm 5.8$ & $27.3 \pm 4.6$ & $<0.001$ \\
\hline SBP & $120.8 \pm 13.6$ & $115.9 \pm 12.7$ & 0.049 \\
\hline DBP & $77.1 \pm 11.8$ & $74.6 \pm 10.2$ & 0.243 \\
\hline Sleep efficacy & $89.9 \pm 12.3$ & $91.0 \pm 13.4$ & 0.649 \\
\hline Sleep duration & $370.6 \pm 65.9$ & $373.6 \pm 48.3$ & 0.798 \\
\hline REM & $38.7 \pm 26.4$ & $46.4 \pm 26.9$ & 0.126 \\
\hline PLM & $3(0-11)$ & $1(0-3)$ & 0.034 \\
\hline Smoking & $42(41.2)$ & $16(41.0)$ & 0.987 \\
\hline Alcohol & $16(15.7)$ & $0(0.0)$ & 0.006 \\
\hline RLS & $12(11.8)$ & $1(2.6)$ & 0.112 \\
\hline $\begin{array}{l}\text { *Continuous data are expressed as mean } \pm \text { standard deviation and median (25-75\%), and categorical data are expressed as } \mathrm{n} \text { (\%). OSAS: Obstructive sleep apnea syndrome, } \\
\text { BMI: Body mass index, SBP: systolic blood pressure, DBP: diastolic blood pressure, REM: Rapid eye movements, PLM: Periodic leg movements, RLS: Restless leg syndrome }\end{array}$ \\
\hline
\end{tabular}


Table 2. Comparison of the study group by the presence of periodic leg movements

\begin{tabular}{|l|l|l|l|}
\hline & PLMI $\geq 5(\mathrm{n}=46)$ & PLMI $<5(\mathrm{n}=95)$ & $\mathrm{p}$ \\
\hline AHI & $40.2 \pm 28.6$ & $18.4 \pm 22.4$ & $<0.001$ \\
\hline Age & $50.4 \pm 12.1$ & $45.7 \pm 10.6$ & 0.020 \\
\hline BMI & $32.9 \pm 7.5$ & $29.2 \pm 4.4$ & 0.002 \\
\hline SBP & $124.1 \pm 14.8$ & $117.2 \pm 12.3$ & 0.004 \\
\hline DBP & $80.0 \pm 10.3$ & $74.7 \pm 11.6$ & 0.010 \\
\hline Sleep efficacy & $89.8 \pm 13.1$ & $90.4 \pm 12.3$ & 0.763 \\
\hline Sleep duration & $373.8 \pm 68.3$ & $370.3 \pm 58.2$ & 0.758 \\
\hline REM & $31.3 \pm 25.5$ & $45.5 \pm 26.1$ & 0.003 \\
\hline Smoking & $17(37.0)$ & $41(43.2)$ & 0.483 \\
\hline Alcohol & $5(10.9)$ & $11(11.6)$ & 0.901 \\
\hline RLS & $7(15.2)$ & $6(6.3)$ & 0.119 \\
\hline $\begin{array}{l}\text { *Continuous data are expressed as mean } \pm \text { standard deviation, and categorical data are expressed as } \mathrm{n}(\%), \text { OSAS: Obstructive sleep apnea syndrome, AHI: Apnea- } \\
\text { hypopnea index, BMI: Body mass index, SBP: Systolic blood pressure, DBP: Diastolic blood pressure, REM: Rapid eye movements, PLMI: Periodic leg movements index, } \\
\text { RLS: Restless leg syndrome }\end{array}$ & \\
\hline
\end{tabular}

Table 3. Clinical and polysomnographic effects of the severity of obstructive sleep apnea syndrome

\begin{tabular}{|c|c|c|c|c|}
\hline & Mild (5-15) $(n=31)$ & Moderate $(16-30)(n=24)$ & Severe $(>30)(n=47)$ & $\mathrm{p}$ \\
\hline AHI & $44.2 \pm 11.5$ & $51.8 \pm 9.1$ & $51.5 \pm 11.4$ & 0.009 \\
\hline Age & $28.7 \pm 3.0$ & $28.8 \pm 3.3$ & $34.9 \pm 6.5$ & $<0.001$ \\
\hline BMI & $118.4 \pm 11.9$ & $116.7 \pm 12.7$ & $124.5 \pm 14.4$ & 0.035 \\
\hline SBP & $75.2 \pm 9.6$ & $75.4 \pm 10.6$ & $79.3 \pm 13.5$ & 0.228 \\
\hline DBP & $91.4 \pm 12.2$ & $86.7 \pm 12.0$ & $90.6 \pm 12.4$ & 0.332 \\
\hline Sleep efficacy & $371.5 \pm 67.9$ & $352.3 \pm 57.9$ & $379.5 \pm 67.9$ & 0.260 \\
\hline Sleep duration & $43.9 \pm 23.8$ & $45.9 \pm 28.7$ & $31.7 \pm 25.5$ & 0.040 \\
\hline REM & $0(0-4)$ & $1.5(0-9)$ & $7(0-15)$ & 0.007 \\
\hline Smoking & $10(32.3)$ & $10(41.7)$ & $22(46.8)$ & 0.441 \\
\hline Alcohol & $2(6.5)$ & $4(16.7)$ & $10(21.3)$ & 0.209 \\
\hline RLS & $3(9.7)$ & $5(20.8)$ & $4(8.5)$ & 0.285 \\
\hline
\end{tabular}

reports, which suggests that PLM might be associated with severe OSAS. Several studies have associated PLM with hypertension, increased cardiovascular and cardiac arrhythmia risk, and also in patients without sleep apnea $(19,20,21)$. In our study, systolic blood pressure was significantly higher in patients with severe OSAS, but diastolic blood pressure was comparable between the groups (mild, moderate, and severe OSAS groups). However, both systolic and diastolic blood pressures were significantly higher in patients with OSAS and PLM. In their 2014 study, Dean et al. (12) reported that PLM (PLMI $\geq 5$ ) was associated with higher diastolic blood pressure irrespective of AHI. The presence of PLM in patients with OSAS may be a factor of increased oxidative stress. Elevated systolic and diastolic blood pressure in patients with hypertension carries greater risk compared with isolated elevation of systolic blood pressure (22). Thus, the presence of PLM in patients with
OSAS contributes to vascular risk by increasing diastolic blood pressure. Another study reported that PLM also caused increased blood pressure and heart rate in healthy individuals without OSAS (11).

In our study, BMI was statistically significantly higher in the OSAS group, and severe OSAS was determined in all patients with BMI greater than 35. Obesity is one of the most important risk factors for OSAS and increased weight is known to be associated with increased disease severity, whereas weight loss is associated with decreased disease severity. Hypertension was more common in the OSAS group.

Consequently, the results of our study demonstrate that PLM is significantly more common in patients with OSAS, particularly in those with severe disease. The presence of PLM indicates a different and more risky group among patients with OSAS. Additionally, 
diastolic blood pressure was significantly higher in patients with PLM; although it did not differ between control and OSAS groups, or between OSAS subgroups. The independent effect of PLM on other parameters could not be investigated in our study due to the limited number of patients. Further studies on greater patient populations should be performed to enlighten the independent effects of PLM.

Ethics Committee Approval: This study has been approved by the Ethics Committee of Mersin University Medical Faculty. Patient Consent: All study participants provided written informed consent. Concept: Osman Özgür Yalın, İbrahim Arda Yılmaz, Okan Doğu, Design: Osman Özgür Yalın, İbrahim Arda Yilmaz, Okan Doğu, Data Collection or Processing: Osman Özgür Yalın, Mehmet Ali Sungur, Analysis or Interpretation: Osman Özgür Yalın, Mehmet Ali Sungur, Literature Search: Osman Özgür Yalın, Writing: Osman Özgür Yalın, İbrahim Arda Yilmaz, Peer-review: Externally peer-reviewed. Conflict of Interest: Authors declare no conflicts of interest regarding this manuscript. Financial Disclosure: Our study has not received financial supports from any institution or person.

\section{References}

1. Guilleminault C, Tilkian A, Dement WC. The sleep apnea syndromes. Ann Rev Med 1976;27:465-484.

2. Young T, Palta M, Dempsey J, Skatrud J, Weber S, Badr S. The ocurrence of sleep-disordered breathing among middle-aged adults. N Engl J Med 1993;328:1230-1235.

3. Marshall NS, Wong KK, Liu PY, Cullen SR, Knuiman MW, Grunstein RR. Sleep apnea as an independent risk factor for all-cause mortality: the Busselton Health Study. Sleep 2008;31:1079-1085.

4. Torre-Bouscoulet L, Castorena-Maldonado A, Sada-Ovalle I, Meza-Vargas MS Mechanisms of cardiovascular damage in obstructive sleep apnea]. Rev Invest Clin 2008;60:502-516.

5. Bixler EO, Kales A, Vela-Bueno A, Jacoby JA, Scarone S, Soldatos CR Nocturnal myoclonus and nocturnal myoclonic activity in a normal population. Res Commun Chem Pathol Parmacol 1982;36:129-140.

6. Al-Alawi A, Mulgrew A, Tench E, Ryan CF. Prevalence, risk factors and impact on daytime sleepiness and hypertension of periodic leg movements with arousals in patients with obstructive sleep apnea. J Clin Sleep Med 2006;15:2:281-287.

7. Ohayan MM, Roth T. Prevalance of restless legs syndrome and periodic limb movement disorder in the general population. J Psychosomc Res 2002;53:547554
8. Hornyak M, Feige B, Riemann D, Voderholzer U. Periodic leg movements in sleep and periodic limb movement disorder: prevalence, clinical significance and treatment. Sleep Med Rev 2006;10:169-177.

9. Iriarte J, Murie-Fernandez M, Toledo E, Urrestarazu E, Alegre M, Viteri C, Salvador J, Baptista P, Alcaide B, Artieda J. Sleep Structure in Patients With Periodic Limb Movements and Obstructive Sleep Apnea Syndrome. J Clin Neurophysiol 2009;26:267-271.

10. Alessandria M, Provini F. Periodic limb movements during sleep: A new sleeprelated cardiovascular risk factor? Front Neurol 2013;12;4:116.

11. Koo BB, Blackwell T, Ancoli-Israel S, Stone KL, Stefanick ML, Redline S; Osteoporotic Fractures in Men (MrOS) Study Group. Association of incident cardiovascular disease with periodic limb movements during sleep in older men: outcomes of sleep disorders in older men (MrOs) study. Circulation 2011;124:1223-1231.

12. Dean DA, Wang R, Jacobs DR, Duprez D, Punjabi NM, Zee PC, Shea S, Watson $\mathrm{K}$, Redline S. A Systematic assessment of the association of polysomnographic indices with blood pressure: the multi-ethnic study of atherosclerosis (MESA). Sleep 2015;38:587-596.

13. Iber C, Ancoli-Israel S, Chesson AL, Quan SF; for the American Academy of Sleep Medicine. The AASM Manual for the Scoring of Sleep and Associated Events: Rules, terminology, and technical specifications, 1st ed. Westchester, IL: American Academy of Sleep Medicine, 2007.

14. Periodic limb movement disorder. In: The International Classification of Sleep Disorders, Revised Diagnostic and Coding Manual, 2rd ed. Westchester, Illinois: American Academy of Sleep Medicine, 2005;65-68.

15. Haba-Rubio J, Staner L, Krieger J, Macher JP. Periodic limb movements and sleepiness in obstructive sleep apnea patients. Sleep Med 2005;6:225-229.

16. Baran AS, Richert AC, Douglass AB, May W, Ansarin K. Change in periodic limb movement index during treatment of obstructive sleep apnea with continuous positive airway pressure. Sleep 2003;26:717-720.

17. Carelli G, Krieger J, Calvi-Gries F, Macher JP. Periodic limb movements and obstructive sleep apneas before and after continuous positive airway pressure treatment. J Sleep Res 1999;8:211-216.

18. Manconi M, Zavalko I, Bassetti CL, Colamartino E, Pons M, Ferri R. Respiratory-related leg movements and their relationship with periodic leg movements during sleep. Sleep 2014;37:494-504

19. Wing YK, Zhang J, Ho CK, Au CT, Li AM. Periodic limb movement during sleep is associated with nocturnal hypertension in children. Sleep 2010;33:759765 .

20. Sforza E, Nicolas A, Lavigne G, Gosselin A, Petit D, Montplaisir J. EEG and cardiac activation during periodic leg movements in sleep: support for a hierarchy of arousal responses. Neurology 1999;52:786-791.

21. Winkelman JW. The evoked heart rate response to periodic leg movements of sleep. Sleep 1999;22:575-580.

22. Sun Z, Han X, Zheng L, Zhang X, Li J, Hu D, Sun Y. Subtypes of hypertension and risk of stroke in rural Chinese adults. Am J Hypertens 2014;27:193-198. 